\title{
Time value of the Internet banking adoption and customer trust
}

\author{
Y. T. Chang \\ ESRC Centre for Competition Policy, University of East Anglia, UK
}

\begin{abstract}
Studies on adoption of new technologies have focused mainly on the behaviour of adoption and on efficiency gains from advancement in the state of technology. The contention of this study is that it is more appropriate to regard the adoption of technology in the banking industry in dual aspects by banks and by customers, given the intermediary role of banks. Despite growing interest in e-Commerce and financial activities, consumer choice decisions as to whether to adopt banking on the Internet has not been fully investigated in the literature. Applying data from Korea on the adoption of on-line banking, the study evaluates consumer characteristics that affect the adoption decision. The study focuses insight on whether the time value perceived by consumers affects their adoption decision to banking on the Internet, introducing decision criteria. The study furnishes helpful information for managers in the banking industry, regarding customer characteristics of trust and risk factors that determine adoption of banking on the Internet.

Keywords: consumer adoption, Internet banking, perceived time value, risks and trust.
\end{abstract}

\section{Background}

The banking industry has been significantly influenced by evolution of technology. The growing applications of computerized networks to banking reduced the cost of transaction and increased the speed of service substantially. In particular, the nature of financial intermediaries made banks improve their production technology, focusing especially on distribution of products. In other words, the evolution of banking technology has been mainly driven by changes in distribution channels, such as the development of over-the-counter (OTC), 
automated-teller-machine (ATM), phone banking, tele-banking, personal computer (pc) banking, and, most recently, Internet banking (IB).

Applications of new technologies, including the Internet, have created new methods of doing business. For instance, e-Commerce and e-Finance have clearly changed the business environment. However, there are only a few studies on consumer behaviour, relative to the vast amount of literature on the behaviour of firms regarding technology adoption, especially in the field of banking and finance. The paper posits that customer trust and risks associated with Internet banking are useful areas of investigation, and that perceived time value of Internet banking adoption is one of the important customer characteristics for the Internet banking adoption.

This paper uses on-line survey data from Korea on Internet banking to analyze the Internet banking adoption pattern across customers. The determinants of IB adoption by customers are identified in a dynamic framework, in order to explain why new banking technologies are not always taken up by the mass market. Differences in the characteristics of early adopters and late delayed adopters are presented in the paper, while customer trust and risks are further discussed for those who have not yet adopted Internet banking.

In the context of trust and risks, the evolution of new technologies in banking and finance has raised additional concerns. As indicated in the survey by the Bank of International Settlements BIS [1], most governments believe that new supervisory or regulatory measures are necessary for Internet banking, although it will take time for them to prepare prudential regulatory guidelines. On the basis of results in this paper, the study shows that the relevant banking regulation has an important implication for adoption of a new banking technology.

The next section describes the new banking technology of Internet banking and factors likely to affect its diffusion, followed by an investigation of the theoretical and empirical literature. The study then presents a duration model for Internet banking adoption and the results, with further discussion on factors preventing Internet banking adoption. The last section concludes with discussions of policy.

\section{Introduction}

One could notice that the evolution of banking technology from CD and ATM to Internet makes banking transactions more mobile (or less location restricted) at a lower fee at the terminal. In addition, the Internet added a new feature of information search in banking, when it retains the advantage of various information types, e.g. in text and audio-visual, which are furnished by CD and ATM. However, despite the benefits of Internet banking, this medium has not yet replaced traditional banking channels, and the banking industry seems to maintain the multi-channel distribution approach.

Since banking technology has been deployed in pursuit of reduction of distribution costs, Internet banking can be considered as a process innovation, with which both banks and customers save time and money. It also allows new customers to visit virtual banks through the public Web network, while phone 
banking and personal computer banking provide only a closed network limited to the existing clients.

Increasing competition among the leading banks also promotes product and service differentiation. Despite the nationwide Internet banking system developed in 1999 by the consortium led by Korea Telecom and several banks, most leading Internet banking firms now use their own system to differentiate from rivals. Currently, all 17 commercial banks in Korea are offering Internet banking. Although they may vary, four main areas of Internet banking services are information search engine, balance check, fund transfer, and loans, in addition to the basic services, such as opening an account and financial product sales. Internet banking does not have the same capacity as CDs and ATMs in delivering cash; however, there are numerous informational features which enable customers to search for appropriate products and services, make a decision, and act on it over the Internet. One important observation to make is that customers need to become more proactive in their information search, in the absence of bank tellers or financial advisors on the telephone.

\section{Focus}

Davies [2] indicates that society fully benefits from a process or product innovation only when the innovation is diffused enough to enhance the productivity of firms or the utility of consumers. However, most of the earlier literature on technological progress focused on the behaviour of firms, analyzing how process innovation would improve its productivity, while the consumer behaviour in relation to innovation has been less frequently discussed in the literature. Gourlay and Pentecost [3] indicate that the inter-firm diffusion of new technology has been relatively less researched for the financial industry, compared to other industries. In particular, study on customer behaviour of financial technology adoption is almost next to none.

Mansfield [4] indicates that commonly used epidemic models of diffusion can draw an analogy between the contact among firms or consumers and the spread of disease in an epidemic sense. For example, some consumers adopt a new technology before others, because they happen to become infected first. Similarly, some technologies diffuse faster than others, as they are more contagious, due to its profitability and risk factors. On the other hand, Karshenas and Stoneman [5] indicate diffusion into three different mechanisms of rank effects, stock effects, and order effects, which explain the cases where firms with sufficiently high ranking adopt an innovation first, early adopters obtain higher returns on the new technology with diminishing returns in time, and adoption is profitable for only early adopters who secure access to the critical input.

Hannan and McDowell [6] indicate strong evidence for rank effects in the diffusion of ATMs, while rejecting the existence of epidemic effects. However, their approach has to be further tested as they excluded the aspects of consumer adoption. More recently, Akhavein et al. [7] indicates few quantitative studies on the diffusion of new financial technologies and the weakness where the technology is limited to ATMs. 
However, more recent developments in the literature focus on trust and risks associated with the Internet, in general, and unidentified risks in Internet banking and finance, in particular. In the general context, Mansell and Collins [8] furnish a comprehensive collection of recent literature on on-line trust and crime. On the other hand, Kim and Prabhakar [9] indicate that a possible reason for the delayed adoption of the Internet as a retail distribution channel is the lack of trust consumers have in the electronic channel and in Web merchants. Similarly, Bauer and Hein [10] indicate that some of the hesitation to adopt Internet banking is due to perceived risks.

\section{Methodology}

The on-line survey data from Korea were collected by sending out 3200 e-mails to predetermined addresses, based on a systematic and stratified sampling. The explanatory variables included in the analysis were drawn from the data for the following categories: demographics, exposure to Internet banking, awareness, banking behaviour, and customer time value and risks.

A duration model is used in order to investigate the dynamics of the Internet banking adoption process. The determinants of early adopters versus delayed adopters are identified as the data contain the sequential information of adoption time. Given the interest in the length of time that elapsed before customers adopt a new banking technology (Internet banking), a hazard rate is estimated for IB adoption in each month, conditioning on the fact that the customer has not adopted Internet banking by that time, as indicated in eqn. (1).

$$
\begin{aligned}
\lambda(t) & =\lim _{\Delta \rightarrow 0} \frac{\operatorname{Pr}(t \leq T \leq t+\Delta \mid T \geq t)}{\Delta}=\lim _{\Delta \rightarrow 0} \frac{F(t+\Delta)-F(t)}{\Delta S(t)} \\
& =\frac{f(t)}{S(t)}=\lambda p(\lambda t)^{p-1}
\end{aligned}
$$

Then, the probability density function and the associated survivor and failure functions are written as follows:

$$
\begin{gathered}
f(t)=\lambda p(\lambda t)^{p-1} \cdot S(t)=\lambda p(\lambda t)^{p-1} \cdot e^{-(\lambda t)^{p}} \\
S(t)=\operatorname{Pr}(T \succ t)=1-F(t)=e^{-(\lambda t)^{p}} \\
F(t)=\operatorname{Pr}(T \leq t)=1-S(t), \text { where } \lambda \equiv \exp \left(\beta^{\prime} X\right)
\end{gathered}
$$

The hazard rate $\lambda(t)$ appears to be the conditional probability of having an exact spell length of $t$, i.e. adopting Internet banking in interval $[t, t+\Delta t]$, conditional on survival up to time $t$ in equation (1), but one should note that the hazard rate is not a probability in a pure sense, since it can be greater than 1 for 
positive duration dependence $(p \succ 1)$. Now the hazard function is derived by conditioning on survival up to time $t$, and the survival function is written as in equation (3). Subsequently, the failure function takes the form, $1-S(t)$, as in equation (4).

\section{Analysis}

Figure 1 illustrates the initial reasons why customers adopt Internet banking. Not surprisingly, more than $50 \%$ of the respondents indicated 'time saving' as their initial reason for using Internet banking, followed by 'easy payments' $(28 \%)$. This draws research attention to time value of customers and justifies the inclusion of survey response time (a proxy for time value of customers) to the duration analysis.

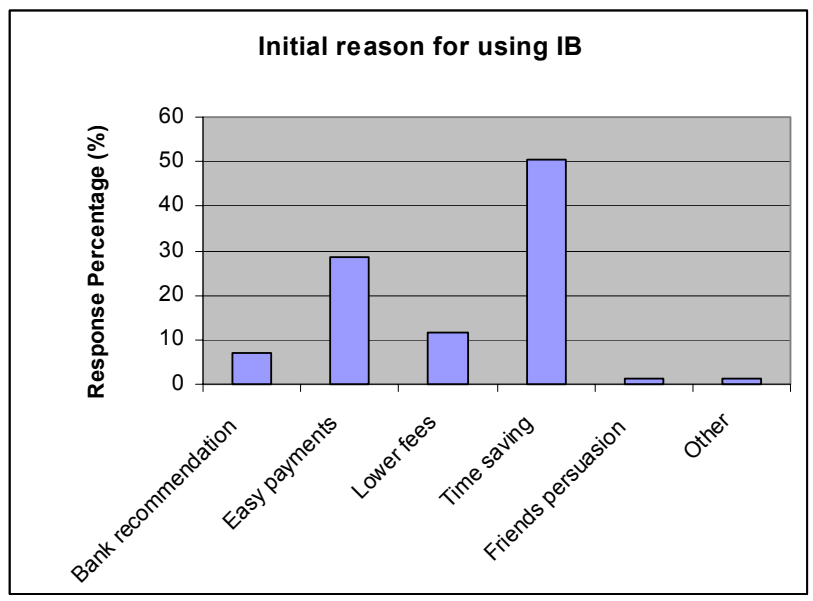

Figure 1: Initial reason for using Internet banking.

On the other hand, those who have not yet adopted Internet banking seem to be most concerned about the on-line security risks (48\%), and many of them do not feel the urge to adopt Internet banking, since they find their banking convenient enough without Internet banking (37\%), as indicated in Figure 2. This obviously brings forward policy discussions on how to regulate and/or manage security risks that arise from Internet banking and how to educate the customers about the benefits of Internet banking. If one believes the arguments indicated by Davies [2], current society is not fully benefiting from the new technology (Internet banking), and there is opportunity for enhancement of social welfare if appropriate policy measures are in place. 


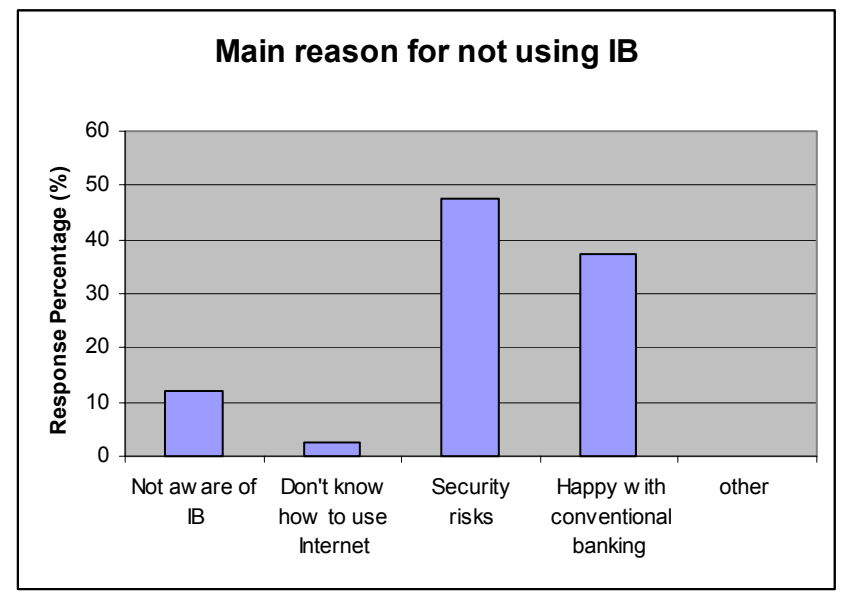

Figure 2: $\quad$ Main reason for not using Internet banking.

The results from the duration analysis of Internet banking adoption are presented in Table 1, of which the second column presents the hazard ratio of each explanatory variable, and the last column shows the predicted marginal effects on adoption time, measured in months. Although the number of variables with statistically significant hazard ratio is limited, most of the variables furnish useful insight.

Gender, marital status, and residential area seem to matter more significantly than other variables. According to the predicted marginal effects on adoption time, males would adopt Internet banking 3.55 months earlier than females at the median, which is not surprising as the IDC [11] report on adoption of wireless communication shows that young male groups are more likely to adopt earlier. Education is not significant in determining customer adoption time of Internet banking, but the duration dependence is negative, which means that further education delays the adoption, perhaps due to risk-aversion. Age does not seem to have much impact, nor does personal income, although the effects seem to be non-linear. Singles are less likely to be early adopters, perhaps given their lower time value or lack of complex banking activities. Another important finding is that residents in the Seoul metropolitan area seem to delay their Internet banking adoption than residents in the provincial areas. This coincides with the time saving reason, as provincial residents may need to travel further to bank branches, and hence they save more incentives to adopt Internet banking than those who have many bank branches or ATM machines nearby in the metropolitan area.

In terms of banking behaviour, Internet banking recommendation does not have much impact on the adoption time or else seems to have rather averse effects, by making customers suspicious and delay the adoption. On the other hand, those who are well aware of interest information tend to adopt Internet banking earlier, given the benefits of fast on-line information services. 
Table 1: Duration estimation results.

\begin{tabular}{|c|c|c|}
\hline Independent variables & $\begin{array}{c}\text { Parametric } \\
\text { Weibull } \\
\text { Hazard ratio }(Z)\end{array}$ & $\begin{array}{c}\text { Marginal effects on } \\
\text { adoption time } \\
\text { (predicted median } \\
\mathrm{t}=22.51 \text { ) } \\
\mathrm{dt} / \mathrm{dx}\end{array}$ \\
\hline Sex $(1=$ male; $0=$ female $)$ & $1.3287(1.78)^{*}$ & $-3.5493 *$ \\
\hline Education $(1=$ Univ/College or above $)$ & $.8738(-.54)$ & 1.5780 \\
\hline Age & $1.0101(.19)$ & -.1206 \\
\hline Age squared & $.9999(-.03)$ & .0002 \\
\hline Personal income & $1.0021(1.13)$ & -.0247 \\
\hline Personal income squared & $.9999(-.96)$ & .0000 \\
\hline Single & $.5166(-1.79)^{*}$ & $8.2873^{*}$ \\
\hline Married & $.5756(-1.49)$ & 6.5485 \\
\hline Outright owned house & $.9200(-.58)$ & .9987 \\
\hline Seoul metropolitan residence & $.7695(-1.81)^{*}$ & $3.0973 *$ \\
\hline IB recommended & $.8143(-1.05)$ & 2.3791 \\
\hline Interest rate awareness & $1.2208(1.42)$ & -2.3753 \\
\hline First mover bank dummy & $1.1424(.74)$ & -1.5661 \\
\hline Market leader bank dummy & $1.2086(1.35)$ & -2.2598 \\
\hline Concerned about bank's reputation & $.9750(-.19)$ & .3049 \\
\hline Survey response time & $1.0108(.81)$ & -.1289 \\
\hline Survey response time squared & $.9999(-.59)$ & .0014 \\
\hline $\operatorname{Ln}(p)$ & $.626(11.15) * * *$ & \\
\hline Parameter P & 1.877 & \\
\hline$\chi^{2}$ & 27.28 & \\
\hline Log likelihood & -264.94 & \\
\hline p-value & .0541 & \\
\hline No. of adoptions & 246 & \\
\hline Time at risk & 6260 & \\
\hline Unobserved heterogeneity & Not significant & \\
\hline \multicolumn{3}{|l|}{ Note: } \\
\hline \multirow{3}{*}{\multicolumn{3}{|c|}{$\begin{array}{l}\text { 1. Standard errors are in the parentheses. } \\
\text { 2. *,**,*** Z-values significant at the } 5 \%, 2.5 \% \text {, and } 1 \% \text { levels respectively. } \\
\text { 3. ***,*** } \chi^{2} \text {-values significant at the } 5 \%, 1 \% \text {, and } 0.1 \% \text { levels respectively. }\end{array}$}} \\
\hline & & \\
\hline & & \\
\hline \multicolumn{3}{|c|}{$\begin{array}{l}\text { 4. Hazard ratio greater than } 1 \text { indicates a positive duration effect on adoption, i.e. more likely to be ar } \\
\text { early adopter. }\end{array}$} \\
\hline
\end{tabular}

However, the hazard ratio does not seem to vary much whether customers are banking with the first Internet banking introducer (order effects or first mover advantage) or the large market leader bank (rank effects), although these two bank dummies have positive duration dependence, i.e. early adoption.

It is disappointing not to see any significant results for reputation criteria of banks and the survey response time, but the signs of the duration dependence support the earlier discussion on customer trust, risks and time value in this section. Customers who care about reputation of banks can be risk averse and hence delay the adoption of Internet banking. By contrast, those who took longer in responding to the survey response are more likely to adopt Internet banking earlier, given their high time value, but at a diminishing rate. 


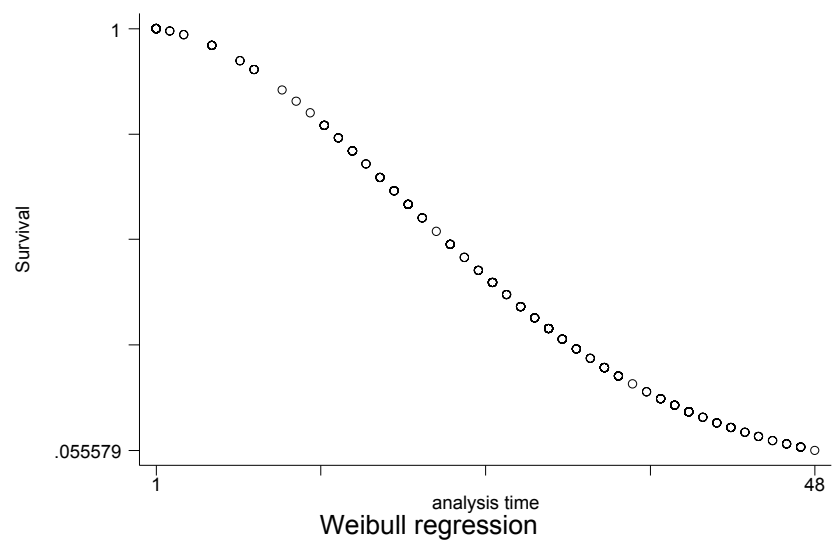

Figure 3: Cumulative survival function for IB non-users using Weibull distribution.

The aggregate estimated pattern of Internet banking adoption is shown in Figure 3, in terms of a survival function, which indicates the number of Internet banking non-users in an S-shaped decline over time. This adoption pattern is also significant as indicated in the duration parameter, $\operatorname{Ln}(p)$. Whether the society can reach the optimal level of Internet banking adoption is up to when and where public policy intervenes in the adoption path of Internet banking. When customers face unidentifiable levels of risk associated with Internet banking, such as human errors in inputting data on the Web or security breakdown on the protection of personal information, public policy has a role in reducing the potential welfare loss associated with the event. We are living in a society increasingly reliant on the Internet, but unfortunately the Internet is mainly unregulated, and the current regulation makes it hard oversee the global network, due to the openness of the Internet.

\section{Conclusion}

The results presented in this study furnish strong evidence that the adoption of Internet banking and its timing are affected by individual characteristics, in particular, gender, marital status and residential area. The analysis also included other individual characteristics in terms of demographics, exposure to the Internet banking, information seeking behaviour, general banking behaviour, and the customer trust and time value, which were not statistically significant, but reassured the time value. However, the duration dependence is significantly positive showing that the earlier literature on epidemic effects of technology diffusion is rightly put forward. More importantly, the descriptive illustration of the initial reasons for Internet banking adoption and the reasons for not adopting it, furnishes us an important field where policy makers and managers could intervene in industry. If security and trust issues are the main concerns for both 
adopters and non-adopters, appropriate public policy and regulation are required to mitigate the potential loss of welfare arising from financial accidents on the Internet as well as to optimise the speed of adoption. The analysis and the discussion in this study only focused on the adoption of Internet banking, but the lessons from Internet banking adoption in Korea shed light on investigation of new industries based on the Internet.

\section{Acknowledgements}

The author wishes to thank Keith Cowling and Jeremy Smith for encouragement and helpful comments, and Margaret Slade, Mike Waterson, Mark Stewart, Wiji Arulampalam, Matthew Haag, Missimiliano Bratti and Morten Hviid, participants at the University of Warwick workshops, the European Association for Research in Industrial Economics Conference 2002, the European Network on Industrial Policy Conference 2002, the University of East Anglia seminars, the International Industrial Organization Conference 2004, and the Australian National University - RSSS seminar for comments and discussions on earlier versions of this study.

\section{References}

[1] BIS, Electronic finance: a new perspective and challenges. Bank for International Settlements, BIS Papers (7), 2001.

[2] Davies, S., The Diffusion of Process Innovations, Cambridge University Press: Cambridge, UK, 1979.

[3] Gourlay, A. \& Pentecost, E., The determinants of technology diffusion: evidence from the UK financial sector. The Manchester School, 70(2), pp. 815-203, 2002.

[4] Mansfield, E., The Economics of Technical Change, Norton: New York, NY, USA, 1968.

[5] Karshenas, M. \& Stoneman, P., Rank, stock, order and epidemic effects in the diffusion of new process technologies: an empirical model. The RAND Journal of Economics, 24(4), pp. 503-528, 1993.

[6] Hannan, T.H. \& McDowell, J.M., The impact of technology adoption on market structure. The Review of Economics and Statistics, 72(1), pp. 164$168,1990$.

[7] Akhavein, J., Frame, W.S. \& White, L.J., The diffusion of financial innovations: an examination of the adoption of small business credit scoring by large banking organizations. Federal Reserve Bank of Atlanta, Working Paper Series 2001-9, 2001.

[8] Mansell, R. \& Collins, B.S., (eds). Trust and Crime in Information Societies, Edward Elgar: Cheltenham, UK and Northampton, MA, USA, 2005.

[9] Kim, K. \& Prabhakar, B., Initial trust and the adoption of $\mathrm{B} 2 \mathrm{C}$ e-commerce: the case of internet banking. The Database for Advances in Information Systems, 35(2), Spring, 2004. 
42 Computational Finance and its Applications II

[10] Bauer, K. \& Hein, S.E., The effect of heterogeneous risk on the early adoption of internet banking technologies. Journal of Banking and Finance, forthcoming 2006.

[11] IDC, Unwiring the internet: end-user perspectives. International Data Corporation Asia / Pacific Report, (AP181102J), 2002. 